\title{
24. A NEW METHOD FOR THE DETERMINATION OF PHYTOHORMONE ACTIVITY
}

\author{
BY GEORGE EDGAR TURFITT \\ From the Division of Biochemistry, London School \\ of Hygiene and Tropical Medicine
}

(Received 26 November 1940)

IN view of the widespread occurrence of phytohormones amongst the bacteria, yeasts and fungi, it would not be surprising to find that growth promotion in these micro-organisms is governed by a mechanism fundamentally similar to that obtaining in the higher plants. No evidence has been obtained [Boysen Jensen, 1932; Nielsen \& Hartelius, 1932; Bonner, 1932; Bünning, 1934]; however, that the phytohormones produced by micro-organisms play any role in their growth. Stimulation of a metabolic activity has, on the other hand, been recorded by Grace [1937], who found that in the fermentation of sugar solutions by baker's yeast, gas production (measured in a saccharimeter after 1 hour) was greatly accelerated as compared with the control by 1 part per million of $\alpha$-naphthylacetic acid, and to a lesser extent by 5 p.p.m. In other experiments, $\frac{1}{10}$ p.p.m. gave considerable stimulation, and as little as $\frac{1}{250}$ p.p.m. had some effect. Concentrations higher than 5 p.p.m. had a repressing action. Similar responses were obtained with $\beta$-indolylacetic acid, its propionic and butyric homologues, and with the $\mathrm{K}$ salt of $\alpha$-naphthylacetic acid, all of which substances are known to possess a stimulating effect on plant growth.

The adoption of some standardized procedure based upon the growth of yeast, or upon the stimulation of its fermentative power, would provide a new and eminently satisfactory method for the rapid testing of materials suspected of phytohormone activity. The work described in this paper was undertaken in order to ascertain the possibility of devising a sorting test along these lines.

\section{EXPERIMENTAL}

The yeast used throughout the work was an English top fermentation type ('D.C.L.' brand), and a separate sample was obtained fresh from the manufacturers for each experiment.

\section{Stimulation of fermentative activity}

A. Grace's technique. The exact conditions under which Grace carried out his experiments are not described in detail in his paper, but an attempt has been made to repeat the work under conditions as nearly identical as the description permitted. The saccharimeter technique possessed obvious inherent defects, and seemed fundamentally unsound especially in that no control could be exercised over the volumes of gas lost through the open limb. As a consequence of uneven and varying sedimentation of the yeast cells, the volumes of gas issuing up either limb showed wide variations in control experiments, the results of which were never sufficiently reproducible to warrant the use of the method for the testing of hormone solutions. 
B. Eudiometer technique. This procedure eliminates the most serious defects of the saccharimeter method, and on theoretical grounds information of a more accurate nature should be obtained by its use. A wide range of experiments has been carried out in order to determine the conditions under which the stimulating effect was most pronounced.

(1) The following were placed in a round-bottom $50 \mathrm{ml}$. flask:

$10 \mathrm{ml}$. water, ${ }^{1}$

$10 \mathrm{ml} .10 \%$ sucrose solution,

$4 \mathrm{ml}$. yeast suspension ( $5 \mathrm{~g}$. yeast/20 ml. water),

$1 \mathrm{ml}$. hormone solution (replaced by water in control experiments),

the flask being then closed with a rubber bung carrying a delivery tube. Five flasks were.prepared in this way, giving the following hormone concentrations: 0 (control), $\frac{1}{10}$ p.p.m., 1 p.p.m., 5 p.p.m., 10 p.p.m. The flasks were placed in a water bath at a constant temperature of $24^{\circ}$, and the $\mathrm{CO}_{2}$ produced during the fermentation was collected in eudiometer tubes over saturated brine, the volumes being noted at intervals. After $24 \mathrm{hr}$. the reaction was very slow; each flask was shaken until no further bubbles of gas were evolved. Several series of control experiments (in which the $1 \mathrm{ml}$. hormone solution was replaced by $1 \mathrm{ml}$. water) were carried out in this way, whilst both $\beta$-indolylacetic acid and $\alpha$-naphthylacetic acid were examined using the same yeast sample. Representative figures are quoted in Table 1.

\section{Täble 1}

\begin{tabular}{|c|c|c|c|c|c|c|c|c|c|c|c|c|c|c|c|}
\hline \multirow{3}{*}{$\begin{array}{l}\text { Concen- } \\
\text { trations } \\
\text { (p.p.m.) .... }\end{array}$} & \multicolumn{10}{|c|}{ Figures are ml. $\mathrm{CO}_{2}$ evolved. } & \multirow{2}{*}{\multicolumn{5}{|c|}{$\alpha$-Naphthylacetic acid }} \\
\hline & \multicolumn{5}{|c|}{ Control experiments } & \multicolumn{5}{|c|}{$\beta$-Indolylacetic acid } & & & & & \\
\hline & 0 & 0 & 0 & 0 & 0 & 0 & $1^{\frac{1}{0}}$ & 1 & 5 & 10 & 0 & $\frac{1}{10}$ & 1 & 5 & 10 \\
\hline Time (hr.) & & & & & & & & & & & & & & & \\
\hline 1 & $14 \cdot 5$ & 10.5 & 15 & $13 \cdot 5$ & 14 & 11.5 & $15 \cdot 5$ & $12 \cdot 5$ & 11.5 & 10.5 & 7 & $8 \cdot 5$ & $10 \cdot 5$ & 8 & 8 \\
\hline 2 & 45 & $35 \cdot 5$ & 47 & 40 & 47 & 3 & 42 & 36 & 33 & 29.5 & $28 \cdot 5$ & 30 & 35 & 27 & 23 \\
\hline 3 & 74 & +60 & 75 & 72 & 78 & 60 & 67 & 6 & 58 & 56 & 58 & 5 & 5 & 5 & 49 \\
\hline 4 & 98 & 77 & 93 & 98 & 104 & 78 & 86 & 80 & 76 & 73 & 77 & 78 & 83 & 74 & 7 \\
\hline 5 & 112 & 94 & 112 & 117 & 124 & 92 & 100 & 97 & 90 & 90 & 93 & 99 & 105 & 94 & 81 \\
\hline 6 & 123 & 107 & 126 & 131 & 136 & 103 & .113 & 108 & 102 & 100 & - & - & - & - & - \\
\hline 24 & 173 & $16 \theta$ & 168 & 169 & 170 & 166 & 177 & 177 & 178 & 173 & 178 & 176 & 179 & 180 & 177 \\
\hline 24 (after & 182 & 180 & 179 & 180 & 182 & 183 & 185 & 188 & 184 & 182 & 184 & 186 & 189 & 185 & 180 \\
\hline
\end{tabular}

From these experiments it would appear that some stimulation does occur as a result of the presence of hormone, the optimum effect being with a concentration of 1 p.p.m., and that with concentrations of more than 5 p.p.m. there is a repressing effect. Neither stimulation nor repression, however, is . very marked.

(2) The bios complex, normally responsible for growth promotion in yeasts; is to some extent synthesized by the organism itself. Thus there exists within the cells a quantity of growth stimulant varying in amount in different samples. In an endeavour to obtain the yeast free from bios and related substances, the yeast samples were washed with $0.9 \% \mathrm{NaCl}$ prior to use. The washing was repeated three times in each case, and the experiment then carried out as described under (1) above. Under these conditions neither stimulation nor 1

1 An aqueous mineral salt solution of the following composition: $\left(\mathrm{NH}_{4}\right)_{2} \mathrm{SO}_{4} 0.2 \%, \mathrm{KH}_{2} \mathrm{PO}_{4}$ $0.2 \%, \mathrm{MgSO}_{4}, 7 \mathrm{H}_{2} \mathrm{O} 0.05 \%, \mathrm{FeSO}_{4}, 7 \mathrm{H}_{2} \mathrm{O} 0.001 \%$, has been substituted in several experiments, but without any appreciable difference in the results. 
repression was exhibited. Although the matter was not further investigated, this negative result with washed yeast tends to suggest that the promotion of fermentation may be dependent upon the presence of a system of substances whose activities are in some way closely inter-related. A similar conclusion has been reached by Kögl [1935] on the functions of the separate fractions of the bios complex in relation to yeast growth.

(3) The precise influence of $\mathrm{O}_{2}$ on the reaction was investigated by carrying out the fermentation of a series of controls under both aerobic and anaerobic conditions.

In the aerobic experiments, individual charges, each in a $60 \mathrm{ml}$. flask, were composed of:

$20 \mathrm{ml}$. water,

$20 \mathrm{ml} .10 \%$ sucrose solution,

$8 \mathrm{ml}$. yeast suspension,

$2 \mathrm{ml}$. water (replacing hormone solution in controls).

$20 \mathrm{~g}$. yeast were suspended in water to a total volume of $80 \mathrm{ml}$. This was aerated with a stream of sterile air during $2 \frac{1}{2} \mathrm{hr}$, when $8 \mathrm{ml}$. of the suspension were used for each experiment. Figures for a representative batch of five flasks are given in Table 2.

Table 2. Control experiments

Figures are $\mathrm{ml} . \mathrm{CO}_{2}$ evolved

\begin{tabular}{|c|c|c|c|c|c|c|c|c|c|c|}
\hline $\begin{array}{l}\text { Time } \\
\text { (hr.) }\end{array}$ & \multicolumn{5}{|c|}{ - Aerobic techniqúe } & \multicolumn{5}{|c|}{ Anaerobic technique } \\
\hline $\begin{array}{l}1 \\
2 \\
3 \\
4\end{array}$ & $\begin{array}{r}8 \\
52 \\
88 \\
118\end{array}$ & $\begin{array}{c}9 \\
51 \cdot 5 \\
91 \cdot 5 \\
123\end{array}$ & $\begin{array}{c}8 \cdot 5 \\
53 \\
89 \cdot 5 \\
131\end{array}$ & $\begin{array}{r}9 \\
48 \\
90 \\
117\end{array}$ & $\begin{array}{c}8 \\
51 \\
88 \cdot 5 \\
133\end{array}$ & $\begin{array}{c}12 \\
47 \\
96 \cdot 5 \\
147\end{array}$ & $\begin{array}{r}11 \\
48 \\
98 \\
148\end{array}$ & $\begin{array}{r}12 \\
48 \cdot 5 \\
98 \\
148\end{array}$ & $\begin{array}{c}10 \cdot 5 \\
46 \cdot 5 \\
97 \\
147\end{array}$ & $\begin{array}{c}11 \\
47 \\
98 \cdot 5 \\
149\end{array}$ \\
\hline
\end{tabular}

For the anaerobic series, charges of similar composition were prepared, but instead of aerating the yeast suspension it was treated with a stream of sterile $\mathrm{N}_{2}$ during $2 \frac{1}{2} \mathrm{hr}$., after which $8 \mathrm{ml}$. were transferred under strietly anaerobic conditions to each of the rest of the charges. For the purpose of this transfer, the apparatus shown in Fig. 1 was constructed. $20 \mathrm{~g}$. yeast were thoroughly ground up with boiled water to give a total volume of $80 \mathrm{ml}$. suspension, which was introduced into flask $A$. A stream of $\mathrm{N}_{2}$ from a cylinder, freed from $\mathrm{O}_{2}$ by a series of alkaline pyrogallol washings, was bubbled through the whole apparatus during a period of $2 \frac{1}{2} \mathrm{hr}$., clips $B$ and $C$ being open. Meanwhile, the ten $60 \mathrm{ml}$. flasks, each containing $20 \mathrm{ml}$. water and $20 \mathrm{ml}$. $10 \%$ sucrose solution, had been heated to boiling for $2 \mathrm{~min}$. to expel air, re-entry of the latter being prevented by Bunsen valves. The flask $A$ was inverted, and the contents transferred to the graduated burette by $\mathrm{N}_{2}$ pressure. The wash bottle $X$ was reversed, the clips being closed during the process to prevent the entrance of air. Each flask in 'turn was attached to the burette ( $Y$ to $Z$ ), and $8 \mathrm{ml}$. yeast suspension introduced. The process to this point was strictly anaerobic, but the anaerobic introduction of hormone solution presents difficulty. The method adopted consisted in preparing the hormone solutions with freshly boiled water, and delivering the required $2 \mathrm{ml}$. by means of a pipette attached to an alkaline pyrogallol wash bottle. The flasks were then incubated in a water bath at $25^{\circ}$ for $2 \mathrm{hr}$., the Bunsen valves being removed under brine, and the $\mathrm{CO}_{2}$ evolved collected in eudiometer tubes. Typical results are shown in Table 2.

(4) The anaerobic technique was undoubtedly the most satisfactory of the various methods investigated, and was employed in the testing of the stimulating 
power of a number of substances. The figures given in Table 3 are representative of those obtained in a wide range of experiments.

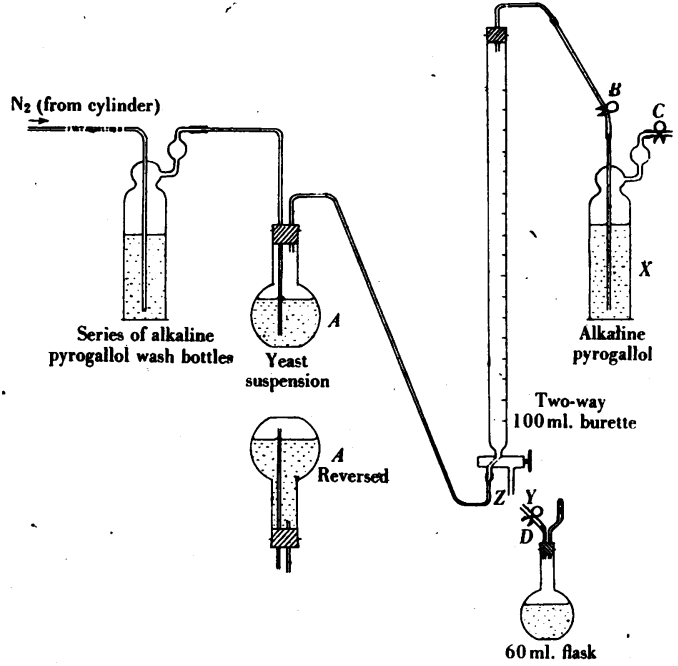

Fig. 1.

In the case of these four compounds both stimulating and repressing effects are obtained. With anthraquinone-1:5-disulphonic acid and anthraquinone-2sulphonic acid, on the other hand, there is no appreciable effect in either direction.

Table 3

Concentration (p.p.m.) ...

\begin{tabular}{ccccccc}
$\begin{array}{c}\text { tration } \\
\text { (p.p.m.) ... }\end{array}$ & \multicolumn{5}{c}{$\beta$-Indolylacetic acid } \\
\cline { 6 - 7 } Time (hr.) & 0 & 1$^{1}$ o & 1 & 5 & 10 \\
1 & $14 \cdot 5$ & 15 & $15 \cdot 5$ & $13 \cdot 5$ & 14 \\
2 & $40 \cdot 5$ & 42 & 41 & 43 & 43 \\
3 & 85 & 87 & 92 & 88 & $87 \cdot 5$ \\
4 & 123 & $132 \cdot 5$ & 137 & 138 & 129
\end{tabular}

Figures are $\mathrm{ml}$. $\mathrm{CO}_{2}$ evolved

\begin{tabular}{lllll}
\multicolumn{4}{c}{$\alpha$-Naphthylacetic acid } \\
0 & $1 \frac{1}{10}$ & 1 & 5 & 10 \\
$12 \cdot 5$ & $13 \cdot 5$ & 17 & 14 & $12 \cdot 5$ \\
41 & 43 & $45 \cdot 5$ & $41 \cdot 5$ & 41 \\
$82 \cdot 5$ & 87 & 92 & 85 & 85 \\
126 & 130 & 141 & 140 & 139
\end{tabular}

Concentration (p.p.m.) ... Phenylacetic acid Time (hr.)

\begin{tabular}{ccccc}
\multicolumn{5}{c}{ Phenylacetic acid } \\
$\overbrace{0}^{1}$ & 10 & 1 & 5 & 10 \\
$10 \cdot 5$ & 10 & $10 \cdot 5$ & $9 \cdot 5$ & $9 \cdot 5$ \\
29 & $29 \cdot 5$ & $29 \cdot 5$ & $27 \cdot 5$ & 28 \\
48 & 51 & 52 & 50 & $50 \cdot 5$ \\
$69 \cdot 5$ & 79 & $80 \cdot 5$ & 78 & $71 \cdot 5$ \\
$88 \cdot 5$ & 99 & $100 \cdot 5$ & 90 & $91 \cdot 5$ \\
$102 \cdot 5$ & 118 & 122 & 110 & 112 \\
179 & 181 & 189 & 183 & 172
\end{tabular}

\begin{tabular}{ccccc}
\multicolumn{4}{c}{$\beta$-Naphthylacetic acid } \\
\hline 0 & $\frac{1}{10}$ & 1 & 5 & 10 \\
10 & $9 \cdot 5$ & $10 \cdot 5$ & 10 & 9 \\
$28 \cdot 5$ & 28 & 30 & 27 & 29 \\
45 & $46 \cdot 5$ & $50 \cdot 5$ & 46 & $48 \cdot 5$ \\
$67 \cdot 5$ & 72 & $77 \cdot 5$ & 70 & 71 \\
$89 \cdot 5$ & 95 & $98 \cdot 5$ & $98 \cdot 5$ & 97 \\
101 & $112 \cdot 5$ & 117 & 111 & 109 \\
177 & 179 & 188 & 180 & $177 \cdot 5$
\end{tabular}

\section{Stimulation of growth}

In an endeavour to obtain optimum and, so far as possible, standardized experimental conditions, a wide range of influencing factors was examined:

I. Culture medium: (a) qualitative and quantitative composition, (b) character of the $\mathrm{C}$ source, (c) character of the $\mathrm{N}$ source, $(d) p \mathrm{H},(e)$ influence of 'growth factors'. 
II. External conditions: (a) temperature, (b) duration of experiment, (c) effect of $\mathrm{O}_{2}$.

III. Inoculum: $(a)$ biological nature, of yeast, $(b)$ physiological condition, (c) initial concentration.

The extensive work of Thorne $[1933,1 ; 1933,2 ; 1936]$ in this field has been followed and, where necessary, supplemented along the lines required by the present problem.

A preliminary experiment was carried out in order to gain some idea of the accuracy of the direct cell-counting method of estimation of the yeast suspension. This is recorded in some detail since an identical experimental technique was adopted in later work with hormone solutions. $100 \mathrm{ml}$. of the culture medium:

$$
\left.\begin{array}{ll}
\mathrm{KH}_{2} \mathrm{PO}_{4} & 2 \mathrm{~g} . \\
\mathrm{MgSO}_{4}, 7 \mathrm{H}_{2} \mathrm{O} & 1 \mathrm{~g} . \\
\mathrm{CaSO}_{4} & 0 \cdot 2 \mathrm{~g} . \\
\mathrm{FeSO}_{4}, 7 \mathrm{H}_{2} \mathrm{O} & 0 \cdot 1 \mathrm{~g} . \\
\left(\mathrm{NH}_{4}\right)_{2} \mathrm{HPO}_{4} & 2 \cdot 5 \mathrm{~g} . \\
\text { Sucrose } & 25 \mathrm{~g} . \\
\text { Distilled water to } 1000 \mathrm{ml}
\end{array}\right\} \begin{array}{r} 
\\
\text { Brought to } p \mathrm{H} 4 \cdot 2 \mathrm{by} \\
\text { addition of } \mathrm{H}_{2} \mathrm{SO}_{4}
\end{array}
$$

were placed in each of three $250 \mathrm{ml}$. conical flasks and sterilized by steaming during $1 \mathrm{hr}$. on each of three successive days. To each flask was added $1.0 \mathrm{ml}$. of a yeast suspension containing 1-2 g. yeast per $100 \mathrm{ml}$.; the seeding rate (i.e. initial count in the culture medium) was thus obtained as approximately 1-3 million cells per ml. The flasks were incubated at $25^{\circ}$, and counts were taken after three days. For the counts a Thoma-Zeiss haemocytometer was employed, all pronounced yeast 'buds' being arbitrarily counted as individual cells.

\begin{tabular}{lrrr} 
& Exp. I & Exp. 2 & Exp. 3 \\
Initial count & 117 & 89 & 97 \\
& 118 & $\mathbf{9 7}$ & 101 \\
& 113 & $\mathbf{9 9}$ & $\mathbf{9 9}$ \\
& $\mathbf{1 1 8}$ & $\mathbf{1 0 7}$ & $\mathbf{9 5}$ \\
& $\mathbf{1 2 6}$ & $\mathbf{9 1}$ & $\mathbf{9 8}$ \\
\cline { 2 - 4 } 3 day count & $\mathbf{1 , 1 8 4 , 0 0 0}$ & $\mathbf{9 7 0 , 0 0 0}$ & $\mathbf{9 8 0 , 0 0 0}$ \\
& $\mathbf{6 3 3}$ & $\mathbf{3 9 9}$ & $\mathbf{5 8 9}$ \\
& $\mathbf{6 3 5}$ & $\mathbf{5 3 3}$ & $\mathbf{6 5 9}$ \\
& $\mathbf{6 0 4}$ & $\mathbf{6 4 8}$ & $\mathbf{4 3 1}$ \\
& $\mathbf{6 6 6}$ & $\mathbf{5 8 0}$ & $\mathbf{5 4 2}$ \\
& $\mathbf{6 , 3 6 0 , 0 0 0}$ & $\mathbf{5 , 4 0 0 , 0 0 0}$ & $\mathbf{5 , 5 0 0 , 0 0 0}$
\end{tabular}

For comparative purposes these figures may conveniently be expressed as 'multiplication rates', i.e. outcrop rate/seeding rate:
(1) $5 \cdot 4$,
(2) $5 \cdot 6$,
(3) $5 \cdot 6$.

The degree of accuracy shown in these preliminary controls was thus of a high order, and the investigation was extended to the use of known plant stimulants, and also to compounds hitherto not examined in this respect. In each case the following procedure was adopted.

Five $250 \mathrm{ml}$. conical flasks, each containing $95 \mathrm{ml}$. synthetic medium were sterilized by steaming. Hormone solutions of different concentrations (which had been prepared with freshly boiled water in order to obtain the as nearly sterile as possible without applying heat) were added in $4 \mathrm{ml}$. quantities, so that the final concentrations in the media were 0 (4 ml. sterile water added), $\frac{1}{10}, 1,5,10$ p.p.m. respectively. Finally, $1 \mathrm{ml}$. yeast suspension was added to each flask. After taking the initial counts, the cultures were incubated (water 


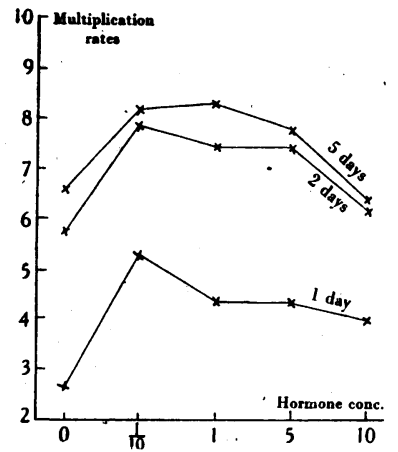

$\beta$-Indolylacetic acid

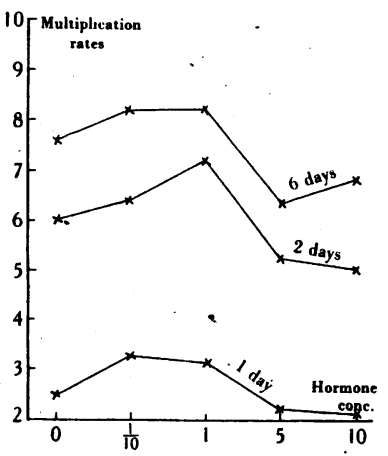

$\beta$-Naphthylacetic acid

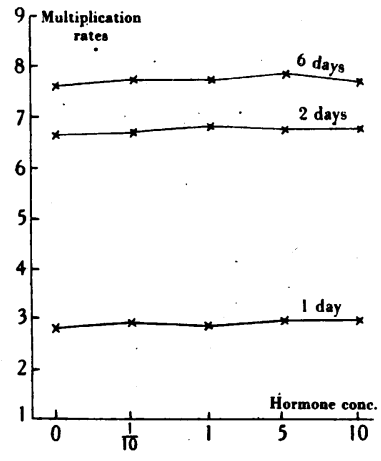

Anthraquinone-2. sulphonic acid

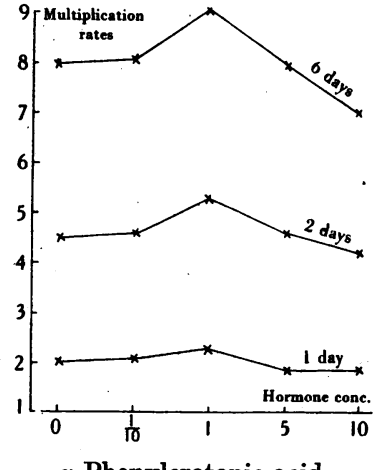

$\alpha$ :Phenylcrotonic acid
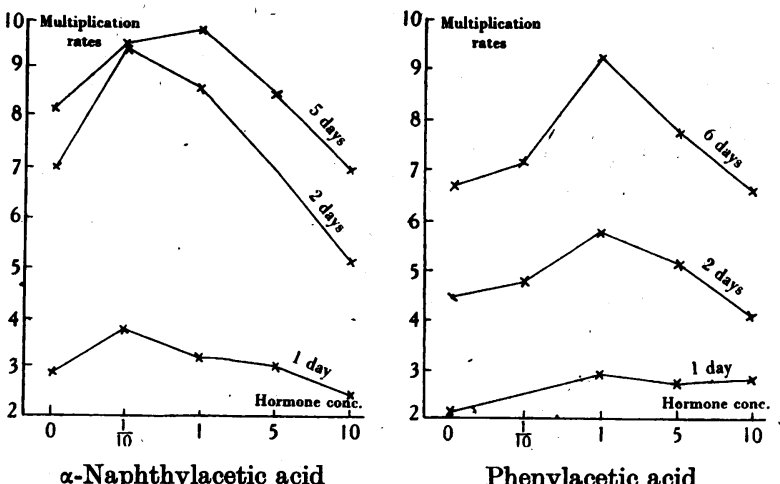

Phenylacetic acid

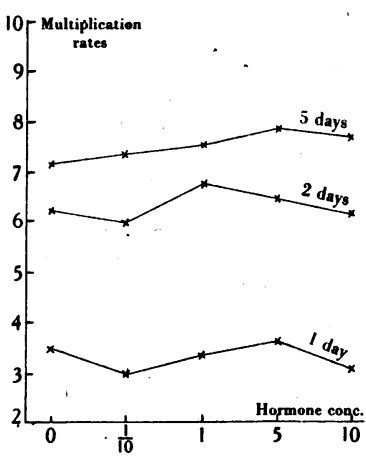

$\alpha$-Anilinopropionic acid

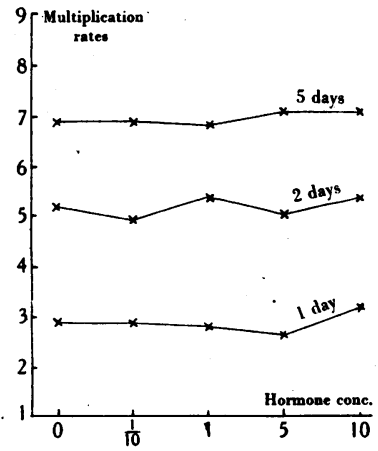

$\mathrm{Na}$ anthracene-9:10-endo$\alpha \beta$-succinate

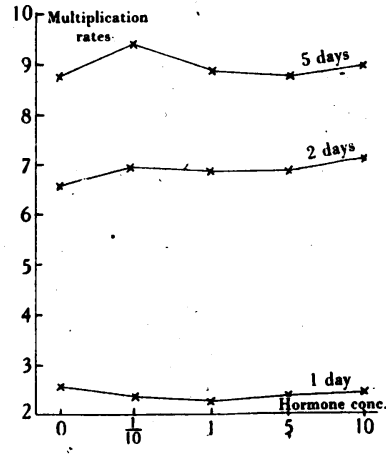

$\alpha$-Anilinovaleric acid

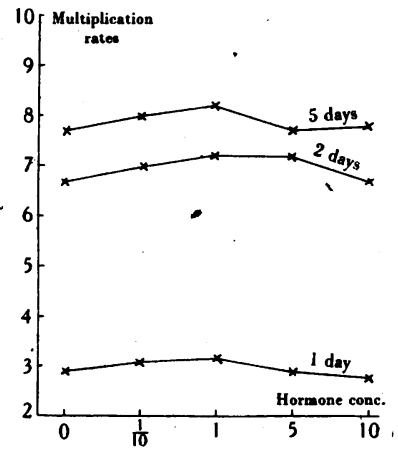

$\alpha$-Phenylpropionic acid
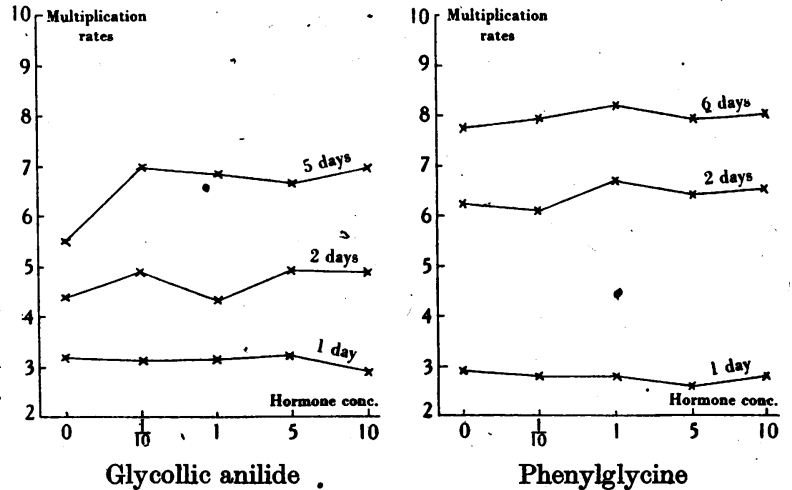

Fig. 2. Hormone concentration given in p.p.m. 
bath) at $25^{\circ}$, and further counts performed after 1,2 and 5 (or 6) days. Interpretation and comparison of the results obtained with the test substances are simplified by the graphical representations in Fig. 2.

In order to indicate the differences to be expected between inactive materials and those having pronounced or weakly stimulating effects, the results obtained with two such inactive substances (viz. anthraquinone-2-sulphonic acid, Na anthracene-9:10-endo- $\alpha \beta$-succinate) have been included.

\section{Discussion}

In an endeavour to obtain comparative data on the fermentation-stimulating activities of various substances, a wide range of experimental conditions has been investigated. The results have served to substantiate the main conclusions of Grace [1937], but the striking stimulating and repressing effects recorded by him have not been confirmed. Since it has been generally accepted that the auxins produced by yeasts and other micro-organisms have no effect on their growth, this stimulation of a metabolic activity of yeast is of considerable interest. The mechanism whereby the phytohormone action is exerted is not clear, but as preliminary washing of the yeast samples before use for fermentation nullifies the stimulating and repressing effect of these substances, it must be concluded that their action is linked with other factors which are removed or deranged by the washing process. Without further investigation of this point it would be premature to discuss the nature of the other factors involved. Went \& Thimann [1937] have shown that a close inter-relation exists between $\beta$-indolylacetic acid, biotin and sucrose in their promotion of root formation on etiolated pea stems. Even the individual members of the bios complex are known [Kögl, 1935], as mentioned above, to be mutually interdependent for the optimum stimulation of yeast growth. This concept of a system of substances with interlocking functions is now established in many natural processes, and the possibility of a phytohormone-bios system cannot be overlooked in connexion with the stimulation of yeast fermentation.

Although fermentation has proved unsatisfactory as the basis of a sorting test for phytohormone activity, a standardized experimental procedure has been evolved, based upon the stimulation of yeast growth. The somewhat lengthy process of testing stimulating power against the higher plants is thus reduced to' the few hours required for the reproduction of yeast cells.

\section{SUMMARY}

1. Fermentation of yeast has been shown to be mildly stimulated by the presence of minute quantities of the known phytohormones, $\beta$-indolylacetic acid, $\alpha$-naphthylacetic acid, $\beta$-naphthylacetic acid, phenylacetic acid.

2 . It has not been found possible to standardize experimental conditions sufficiently to justify the use of the method as a sorting test for substances suspected of phytohormone activity.

3. The effect of washing yeast samples before fermentation is to nullify the stimulating effects ordinarily obtained with phytohormones. This is suggested as tentative evidence for the assumption of a phytohormone-bios system, the action of individual members of which is closely interdependent.

4. Contrary to accepted opinion, evidence has been obtained of the stimulation of yeast growth by phytohormones, and several compounds have been tested for phytohormone activity by observing their effects on yeast growth. 
The author wishes to express his thanks to Prof. H. Raistrick in whose Laboratories this work has been carried out, and to Imperial Chemical Industries (Dyestuffs Group), Ltd., for their kind permission to publish the results given in this paper.

\section{REFERENCES}

Bonner (1932). Biol. Zbl. 52, 565.

Boysen Jensen (1932). Biochem. Z. 250, 270.

Bünning (1934). Ber. dtsch. bot. Ges. 52, 423.

Grace (1937). Canad. J. Res. 15, 544.

Kögl (1935). Ber. dtsch. chem. Ges. 68, 16.

Nielsen \& Hartelius (1932). C.R. Lab. Carlsberg, 19 (8), 1.

Thorne (1933, 1). J. Inst. Brew. 597. - (1933, 2). J. Inst. Brew. 608. (1936). J. Inst. Brew. 15.

Went \& Thimann (1937). Phytohormones. New York. 